\title{
SøREN KiERKEGAARD Y SU INFLUENCIA \\ EN LA POÉTICA DE FRANZ KAFKA ${ }^{1}$
}

\author{
Fabio Bartoli \\ Universidad de Salamanca, España
}

\begin{abstract}
Resumen
Este artículo trata de demostrar que la estética de Kierkegaard influenció la poética de Kafka. El texto parte de una descripción de la vida estética kierkegaardiana, en relación con la seducción y el amor, para determinar su influencia en las novelas El castillo y El proceso. Este análisis conduce a reflexionar, respecto de ambos autores, sobre el papel de la escritura en relación con el amor. Finalmente, se analizará el caso específico de sus respectivas relaciones con el matrimonio para demostrar de qué manera la vida estética descrita por Kierkegaard influenció la poética de Kafka.
\end{abstract}

Palabras clave: Kierkegaard, Kafka, seducción, amor, escritura.

\section{Abstract}

This article demonstrates how Kierkegaard's aesthetics influenced on Kafka's poetics. The text begins with a description of Kierkegaardian aesthetic life, focusing only on the topics of seduction and love. After this, I look for traces of this influence in the novels The Castle and The Process. This first analysis leads me to reflect about the role of writing regarding love in both authors. Finally, I will analyze their relationships with marriage to demonstrate the influence of the aesthetic life described by Kierkegaard on Kafka's poetics.

Keywords: Kierkegaard, Kafka, seduction, love, writing

\section{Introducción}

Bajo el entendido de que Kafka fue un asiduo lector de Kierkegaard, este artículo describirá los elementos de la estética ${ }^{2}$ kierkegaardiana que

${ }^{1}$ Recibido el 8 de octubre de 2019; aceptado el 13 de enero de 2020.

${ }^{2}$ Aquí se hace necesaria de inmediato una precisión terminológica. En este artículo no queremos afirmar que Kierkegaard desarrolló una teoría estética en un sentido riguroso. 
incidieron en la poética kafkiana ${ }^{3}$, en particular se demostrará que Kafka estuvo influenciado de manera decisiva por la lectura de los escritos estéticos de Kierkegaard, pero sobre todo de $O$ lo uno o lo otro ${ }^{4}$. En particular, jugó un papel crucial la primera parte de esta obra, esto es, la referida a la vida estética, influencia que se puede ver de manera más clara en dos tópicos particulares: la seducción y el amor. En virtud de dicha influencia, se hará necesario reflexionar sobre las diferentes concepciones que los dos pensadores tenían sobre el matrimonio, y sobre cómo esto se relaciona directamente con el papel de la literatura en sus vidas. Una vez encontradas las similitudes, se analizarán las eventuales diferencias entre ambas posturas para destacar cuáles fueron los elementos de los que Kafka se sirvió, después de haber asimilado la estética de Kierkegaard, para el desarrollo de su poética. Esta será, pues, la tarea central de este trabajo. Desde un punto de vista metodológico, esto se hará comparando unos pasajes de los escritos estéticos de Kierkegaard con los escritos de Kafka que consideramos relevantes para evidenciar las similitudes entre las dos concepciones estéticas, enfocando la atención de vez en vez sobre las temáticas que nos parecen más ilustrativas para el desarrollo de la argumentación.

Esta operación es de la mayor importancia por cuanto desvela un aspecto hasta ahora poco estudiado, esto es, la relevancia de la estética de

Más precisamente, él se preocupó mucho por describir el estilo de vida estético y las consecuencias que este tipo de vida comportaba en el individuo, y es esta parte de su producción literaria la que influenció Kafka y a la cual queremos referirnos. Entonces, en este artículo cuando usemos el término Estética, referido a Kierkegaard, el lector deberá entender la descripción de la vida estética que el danés nos ofrece en sus obras, y no una teoría sistemática de esta disciplina desarrollada por él (Kierkegaard nunca quiso hacer esto). Se han escrito ríos de tinta sobre cuál debería ser el término más adecuado para definir este aspecto del pensamiento kierkegaardiano, sin que hasta ahora los estudiosos hubieran llegado a un acuerdo. Para evitar este problema, nosotros hemos optado por el simple término Estética, que, a lo largo de todo el artículo, tiene que ser entendido en el sentido que acabamos de explicar.

${ }^{3}$ En el caso del término poética con referencia a Kafka tenemos que hacer una precisión similar a la precedente. Cuando en este artículo se habla de la "poética de Kafka" no se hace referencia al hecho de que el escritor checo tuviera, o hubiera querido desarrollar, una teoría poética. No tenemos ningún escrito de él en el que se pueda identificar una intención en ese sentido, y probablemente no existía ninguna voluntad de actuar en esta dirección (es importante recordar la aversión kafkiana hacia el pensamiento sistemático). Por ello, cuando aquí hagamos referencia a la "poética de Kafka" se debe entender como una referencia a las temáticas que, con una mirada a posteriori, se pueden encontrar en sus escritos.

${ }^{4}$ Søren Kierkegaard, O lo uno o lo otro. Un fragmento de vida I, trad. de Begonya Saez Tajafuerce y Darío González, Madrid: Trotta, 2006 y Søren Kierkegaard, O lo uno o lo otro. Un fragmento de vida II, trad. de Begonya Saez Tajafuerce, Madrid: Trotta: 2007. 
Kierkegaard para el desarrollo de la poética de uno de los mayores escritores del siglo XX.

\section{Kafka lector e intérprete de la vida estética de Kierkegaard}

Gracias a los diarios y a la correspondencia que hemos heredado de Kafka, sabemos que su relación con Kierkegaard se puede esquematizar en dos momentos bien distintos de su vida ${ }^{5}$. La primera vez -y la menos importante- que Kafka leyó algo de Kierkegaard se trataba de una antología de fragmentos del diario que escribió a lo largo de su vida ${ }^{6}$. Lo que en ese momento llamó la atención de Kafka fue la pavorosa semejanza entre su situación sentimental con Felice Bauer y la historia de amor entre Kierkegaard y Regine Olsen. De este primer encuentro literario tenemos una anotación en el diario, en la que Kafka reconoce en Kierkegaard a un amigo:

\section{1 de agosto de 1913}

Hoy he conseguido el Libro del juez, de Kierkegaard. Como ya suponía, su caso, a pesar de algunas diferencias esenciales, es semejante al mío, por lo menos se encuentra en el mismo lado del mundo. Me confirma, como un amigo $^{7}$.

Después de este primer acercamiento a la obra de Kierkegaard, Kafka de inmediato hace un paralelismo entre su vida privada y la de aquel. Sin embargo, considerando que esta primera impresión de la obra de Kierkegaard no proviene de una lectura de sus libros publicados, sino de una antología de su diario, se entiende por qué Kafka no dedica ni una palabra al pensamiento "filosófico" de Kierkegaard, prefiriendo centrarse sólo en sus peripecias personales. Es decir, en ese momento Kafka no reflexionó de manera profunda sobre el pensamiento de Kierkegaard, y si bien nunca perderá esta primera impresión de similitud con él, como veremos más adelante, dicha impresión mutará en los años.

${ }^{5}$ Giovanni Pellegrini, La legittimazione di sé. Kafka interprete di Kierkegaard, Turín: Trauben, 2001, p. 39.

${ }^{6}$ La edición que Kafka leyó de esta obra es: Søren Kierkegaard, Bücher des Richters. Ein Tagebücher 1833-1855, en Auszug aus dem Dänischen, ed. por H. Gottsched, Jena y Leipzig: Eugen Diederichs Verlag, 1905.

${ }^{7}$ Franz Kafka, Diarios (1910-1923), trad. de F. Formosa, Barcelona: Fabula Editorial Lumen, 2010, pp. 189-190. 
Años después, en Zürau en el año 1918, Kafka se dedica a una reflexión seria sobre Kierkegaard leyendo y estudiando dos de sus escritos más importantes: O lo uno o lo otro ${ }^{8}$ y Temor y temblor 9 . El contexto de este segundo encuentro es totalmente diferente del primero: valga comenzar señalando que a Kafka le acaban de diagnosticar la mortal tuberculosis. De hecho, en relación con este acontecimiento él ha encontrado la valentía para romper definitivamente el noviazgo con Felice (con quien estaba comprometido durante su primer acercamiento a Kierkegaard), liberándose por fin de esta carga que tanto lo angustiaba ${ }^{10}$ y que le impedía dedicarse con alma, vida y corazón a su verdadera y única vocación: la literatura. Es más, estos dos eventos -la tuberculosis y la ruptura con Felice-lo catapultaron en una nueva fase de su vida; ahora, con su futuro en una dirección mortífera y sin la posibilidad de llevar a cabo una vida de normal hombre burgués y judío, él se ve obligado a justificar esta disposición del alma que siempre lo ha transportado hacia la vida literaria, aun a costa de su vida ${ }^{11}$.

En esta nueva condición existencial Kafka comienza una seria comparación con los estadios de la vida descritos por Kierkegaard. La literatura especializada ya se ha ocupado mucho de las reflexiones que Kafka hizo sobre la esfera religiosa de la vida, sobre todo careándose con la figura bíblica de Abraham ${ }^{12}$. Nosotros creemos que, en realidad, este no

${ }^{8}$ Kierkegaard, O lo uno o lo otro. Un fragmento de vida volumen I y II.

${ }^{9}$ Søren Kierkegaard, La repetición. Temor y temblor, trad. de D. González y O. Parcero, Madrid: Trotta, 2019.

${ }^{10}$ Cfr. Anthony Northey, "Family", en Franz Kafka in Context, ed. por Caroline Duttinger, Cambridge: Cambridge University Press, 2018, pp. 9-10.

11 Tenemos que señalar que en un cierto sentido Kafka piensa que se enfermó de tuberculosis a causa de sus penas interiores, las cuales lo laceraban por la fuerte tensión entre la vida matrimonial y la vida literaria; él expresa este pensamiento en una de las últimas cartas a Felice, fechada el 1 de octubre de 1917: "En mi interior hay dos seres que se combaten [...]. Sobre las vicisitudes de la lucha has sido informada a lo largo de cinco años [...]. Esos dos combatientes que hay en mí, o mejor dicho, de cuya lucha -salvo por un pequeño resto martirizado- estoy hecho, el uno es bueno y el otro es malo; de vez en cuando intercambian entre sí las máscaras, lo cual viene a introducir una confusión aún mayor en el ya de por sí confuso duelo. [E]l caso es que, en mi fuero interno, ya no tengo a esta enfermedad por una tuberculosis, o al menos no la considero tal primordialmente, sino que la tengo por una quiebra general. [L]a sangre no proviene del pulmón, sino de la estocada, o de una estocada definitiva, de uno de los combatientes. [V] oy a decirte un secreto [...]: jamás recobraré la salud": Franz Kafka, Cartas a Felice, trad. de P. Sarozábal, Madrid: Nórdica Libros, 2013, pp. 810-812.

${ }^{12}$ Cfr. Pellegrini, La legittimazione di sé. Kafka interprete di Kierkegaard; y Leena Eilittä, "Art As religious Commitment: Kafka's Debt to Kierkegaardian Ideas and Their Impact on His Late Stories", German Life and Letters, vol. 53, no. 4, 2000, pp. 499-510. 
fue el aspecto más importante con el cual se enfrentó en estos meses de intensos estudios kierkegaardianos, de hecho, Kafka quedó atrapado por las descripciones de Kierkegaard sobre el estadio estético en la primera parte de O lo uno o lo otro ${ }^{13}$.

En este punto, parece relevante describir los famosos Papeles de $A$, en los cuales Kafka creyó encontrar una descripción del estilo de vida que su pasión literaria lo había forzado a vivir. Por supuesto, no pretendemos tratar todas las temáticas presentes en este largo libro, sino sólo aquellas que nos parecen relevantes para nuestra comparación, y que, en todo caso, son argumentos fundamentales de la obra. Siendo así, nos concentraremos sólo en dos temas enlazados entre ellos: el amor y la seducción.

Siguiendo esta lógica, y como ya hemos dicho, no trataremos toda la obra $O$ lo uno o lo otro, sino sólo su primera parte: la que describe el estilo de vida estético. Esta sección, en la ficción literaria de Kierkegaard, está compuesta por unos escritos que el editor (Victor Eremita) encuentra casualmente en un viejo secretaire, que un día había comprado en una tienda de muebles usados. En el prólogo se cuenta que, después de una atenta lectura, el editor ha decidido publicar todas estas cartas encontradas casualmente porque las considera de enorme interés ${ }^{14}$. Estos papeles hacen parte de una conversación literaria que un esteta (jamás se sabe el verdadero nombre de esta persona que siempre viene llamada A) tiene con un amigo suyo (el Asesor Wilhelm que, a veces, por simetría, viene llamado B). En ella, el primero trata describir su estilo de vida, y el segundo intenta convencerlo de cambiar su modo de vivir a favor de un estilo de vida ético. El reconocimiento de la "paternidad" de los varios escritos no necesita ningún trabajo filológico particularmente elaborado, este resultado se logra fácilmente mirando el estilo de escritura de los papeles: mientras que B redacta sólo (tres) cartas con una grafía muy ordenada, usando un lenguaje bastante linear y sobre papeles en uso de las oficinas burocráticas, la producción literaria de A se distingue por su variedad y eclecticismo. El esteta para comunicar con su amigo usa una gama de estilos de escritura que van desde el aforismo hasta el diario, y que es completamente ajena al estilo de escritura de B.

Toda la parte que así se atribuye al esteta tiene un fin preciso: describir el estilo de vida estético a su interlocutor. Esta parte del libro es una larga

${ }^{13}$ No somos los primeros en darnos cuenta de la importancia que este libro tuvo para Kafka, véase también Giuliano Baioni, Kafka: letteratura ed ebraismo, Turín: Einaudi, 1984, p. 215 y pp. $220-221$.

${ }^{14}$ Kierkegaard, O lo uno o lo otro. Un fragmento de vida I, pp. 29-39. 
disquisición sobre un tema bien específico: la seducción y el estilo de vida que comporta si esta se convierte en el leitmotiv de la existencia. Retratando esta peculiar manera de vivir, la personalidad del seductor toma forma. Aunque en el texto se puede encontrar una descripción bien detallada de dos tipos de seductores diferentes, el Inmediato y el Reflejo, nosotros no vamos a tratarlos, no sólo porque es un trabajo que ya han hecho muchos estudiosos $^{15}$, sino porque Kafka seguramente no se perdió en esta minucia.

En cambio, partiendo de una atenta lectura de las cartas de A, Kafka se conformó con una imagen del seductor que, aunque seguramente Kierkegaard no habría aprobado, se puede considerar más o menos como una síntesis arbitraria de todas estas facetas de la personalidad del seductor, y es de allí que tomó los elementos que podemos encontrar en su poética ${ }^{16}$. Este "prototipo" de seductor se puede describir como una persona apta para vivir sólo en el momento presente, incapaz de concebir el futuro y el pasado: su vida es una infinita sucesión de instantes no relacionados entre ellos. Esta inhabilidad se refleja en su estilo de vida: para no caer víctima de la profunda angustia que comporta su desgraciado modo de ser, él decide invertir todo su tiempo en vanas conquistas que sirven sólo para distraerlo de su estado lamentable, sin tener nunca la intención de construir una verdadera relación sentimental con la víctima de turno. Su peor enemigo es el aburrimiento, uno que está siempre asechándolo ${ }^{17}$. Esta es una vida que

15 Para unos ejemplos, cfr. Simonella Davini, La maschera estetica del seduttore, en Maschere kierkegaardiane, ed. por Leonardo Amoroso, Turín: Rosenberg\&Sellier, 1990; Sylvia Walsh Utterback, "Don Juan and the Representation of Spiritual Sensuousness", Journal of the American Academy of Religion, vol. 47, no. 4., 1979, pp. 627-644; Héctor Rodríguez, "La seducción estética y el amor infeliz en Søren Kierkegaard", Cuadernos de filosofía latinoamericana, vol. 30, no. 101, 2009, pp. 97-110; y Jennifer Hincapié Sánchez, "De estética y seducción en "Los eróticos inmediatos, o el erotismo musical", en De ironía y seducción. Ensayos sobre Kierkegaard, ed. por Jennifer Hincapié Sánchez, Medellín: Editorial Universidad de Antioquia 2019, pp. 95-117.

${ }^{16}$ No pretendemos afirmar que Kafka estuvo influenciado únicamente por los elementos que tratamos en este artículo, de hecho, hay estudios que abarcan el problema de las influencias estéticas que se pueden evidenciar en su obra; sin embargo, en nuestra opinión, no revelan, en sus justas proporciones, la importancia que tuvo Kierkegaard. Es por eso por lo que este trabajo se centra sólo en la relación Kierkegaard/Kafka. Para un ejemplo de textos que analizan las distintas tradiciones que conviven en Kafka, véase Leopoldo La Rubia de Prado, El laberinto kafkiano. Claves hermenéuticas para la comprensión de la obra de Franz Kafka y la categoría estética de lo "kafkiano", Tesis de Doctorado, Madrid: UNED, 1999.

${ }^{17}$ Para ver la importancia del aburrimiento en la vida estética basta notar que uno de los textos de A es La rotación de los cultivos. Ensayo para una doctrina de prudencia social, en Kierkegaard, O lo uno o lo otro. Un fragmento de vida I, pp. 289-307, dedicado exclusi- 
está siempre en vilo, como si estuviese corriendo continuamente en el filo de una navaja, basta una nimiedad para que emerja el vacío escalofriante que lo corroe, precipitándolo en un terrible estado de desesperación.

Como si este trágico escenario no fuera suficiente para describir los efectos que el estilo de vida estético puede tener sobre la persona que lo conduce, surge otra consecuencia: este comportamiento borra, inexorablemente, la personalidad del seductor ${ }^{18}$. El hecho de que siempre haya una nueva mujer por conquistar significa que el seductor tiene que modificar su personalidad, adaptándola a los gustos de la favorita del momento. En ese sentido, el seductor está obligado a llevar una máscara ${ }^{19}$ en cada situación, lo que trae consigo el efecto secundario de destruir progresivamente su esencia real. Este triste cuadro se completa destacando otro importante aspecto del estilo de vida estético: el seductor escoge no escoger. Esto comporta su renuncia a la determinación de sí mismo como individuo. Él se queda en un estado de indeterminación, una miríada de posibilidades incumplidas ${ }^{20}$.

Ahora bien, este cuadro que Kafka se hizo del seductor y del estilo de vida estético corresponde claramente a la opinión que tenía de sí mismo y de su estilo de vida, y es cierto que esto afectó de forma crucial el desarrollo de su vida y de su poética ${ }^{21}$. En las cartas de A, el escritor checo cree encontrar la justificación o, en el peor de los casos, la descripción de su estilo de vida: una vida completamente dedicada a la literatura. Citando a Baioni: "Kafka ve en Kierkegaard, sobre todo, el juez del hombre de la vida estética. No es su dialéctica lo que le interesa, entre otras cosas, porque siendo incapaz de abstracciones conceptuales, no logra aprehenderla. Para él, mucho más evidente es el retrato que Kierkegaard hizo del esteta, el hombre con infinitas posibilidades, quien, persiguiendo el placer de la representación, cae presa de la angustia y desesperación" 22 .

Hasta aquí hemos recorrido senderos conocidos para describir los aspectos de la estética de Kierkegaard que más influyeron en la vida y la poética de Kafka. Esto ha sido propedéutico para desarrollar la segunda parte de este artículo y mostrar cómo se encuentran en los escritos de Kafka estos temas que acabamos de describir.

vamente a ofrecer consejos para luchar contra el aburrimiento.

${ }^{18}$ Kierkegaard, O lo uno o lo otro. Un fragmento de vida I, passim.

${ }^{19}$ Para profundizar este tema se reenvía a Davini, La maschera estetica del seduttore.

${ }^{20}$ Kierkegaard, O lo uno o lo otro. Un fragmento de vida I, passim.

${ }^{21}$ De la misma opinión es Baioni, Kafka: letteratura ed ebraismo, p. 221.

22 Baioni, Kafka: letteratura ed ebraismo, pp. 220- 221 (Traducción propia). 


\section{Influencia de la vida estética de Kierkegaard en las novelas de Kafka}

Considerando que un análisis exhaustivo de todo el trabajo del escritor checo excedería de manera excesiva el breve espacio de un artículo, nos concentraremos en las dos novelas más importantes de Kafka, El proceso ${ }^{23}$ y El castillo ${ }^{24}$, porque en estas se puede ver con claridad la relevancia de la influencia de la estética de Kierkegaard. De hecho, la seducción es un tópico recurrente en ambas novelas. Como pasa con el seductor descrito por Kierkegaard en $O$ lo uno o lo otro, los protagonistas de estas novelas kafkianas (K y K) practican la seducción siempre persiguiendo un objetivo, y nunca de manera desinteresada. Mientras que el primero busca mujeres que le hagan olvidar su desesperación, aunque sea por un instante; los $\mathrm{K}$ seducen muchachas para encontrar aliadas en las vicisitudes de la vida. De hecho, sin lugar a duda, en estas novelas se encuentra siempre una mujer que el protagonista ha seducido y que está dispuesta a prestarle ayuda, sin la cual el seductor, sobre todo en El castillo, se quedaría completamente solo, ignorado por el resto del mundo.

De esta situación es importante resaltar otra peculiaridad que ilustra el tema de nuestro análisis: frecuentemente estas ayudas que los $\mathrm{K}$ buscan y consiguen por medio de la seducción son deletéreas y logran sólo empeorar su situación inicial. No hace falta recordar las nefastas consecuencias que tiene la historia de amor entre $\mathrm{K}$ y Frieda en El castillo. Seduciendo una amante de uno de los miembros del Castillo, esto es, de Klamm, el protagonista no consigue ser aceptado de golpe en la comunidad, complicando su originaria posibilidad de aceptación ${ }^{25}$.

Ya con este análisis se puede delinear la percepción que Kafka tenía de las relaciones con las mujeres: se deposita en estas relaciones muchas esperanzas, pero siempre terminan muy mal. Sin embargo, en este punto surge otra pregunta: por ahora hemos considerado sólo la seducción, entendida como el acto físico, pero si esta primera aproximación sexual se convierte en un verdadero sentimiento, ¿qué pasa? ¿La situación que acabamos de describir cambia o la sospecha hacia las mujeres se mantiene invariable?

${ }^{23}$ Franz Kafka, El proceso, en Obras completas I, ed. por Jordi Llovet, trad. de Miguel Sáenz, Barcelona: Galaxia Gutenberg, 1999.

${ }^{24}$ Franz Kafka, El castillo, en Obras completas I, ed. por Jordi Llovet, trad. de Miguel Sáenz, Barcelona: Galaxia Gutenberg, 1999.

${ }^{25}$ Ibíd. 
En realidad, si bien esta cuestión es importante, es muy difícil aclararla mediante el estudio de estas dos novelas, pues en ellas la seducción, desde el punto de vista masculino, nunca se transforma en una relación sentimental, y esta peculiaridad nos parece que agrega otro elemento a la concepción kafkiana del amor: en su mundo, para la mayor parte de las personas el amor no es una situación común, y seguramente no es el fundamento de las relaciones entre hombre y mujer.

En todo caso, hay otra vía que podemos tomar para tratar de hacernos una idea más clara sobre la posición de Kafka respecto del amor, esto es, buscando alguna referencia a éste entre sus cartas privadas ${ }^{26}$. Allí, una de las fuentes más ricas en relación con este tema la ofrecen las cartas a Felice ${ }^{27}$, lo que constituye una afortunada coincidencia, porque leyendo estas epístolas nos llama la atención que esta historia de amor tiene muchas semejanzas con la relación entre Kierkegaard y Regine Olsen. Nuestra intuición está confirmada por el hecho de que el mismo Kafka se dio cuenta de esta peculiaridad cuando, leyendo al danés por primera vez, anotó en su diario que veía en él un $\operatorname{amigo}^{28}$ por haber estado involucrado en penas de amores increíblemente semejantes a las suyas con Felice.

Una breve descripción de las dos situaciones podría resultar oportuna. Ambos, después de haber seducido y conquistado una mujer deciden anular el compromiso que tanto habían dicho querer ${ }^{29}$. Desde esta similar aversión al matrimonio, y a la vida que comporta, podemos extraer una interpretación interesante. El matrimonio -entonces el amor- permite al hombre determinarse como persona, y es un paso fundamental para lograr una vida plena y socialmente aceptada por la comunidad, de modo que un hombre se sienta realizado tanto en la esfera privada como en la pública. El problema es que esta no es una puerta abierta para todos, un hombre tiene que ser digno, o por lo menos considerarse tal, para poder ingresar. Lo

${ }^{26}$ Una peculiaridad de la obra de Kafka, y de Kierkegaard, es que todo lo que escriben se puede considerar como obras de literatura. Por esto, para delinear la poética de Kafka (sobre todo como la estamos considerando en este artículo) no tenemos ninguna inquietud metodológica en tratar de igual manera las novelas, los cuentos, las cartas y los diarios como si tuvieran la misma naturaleza literaria.

${ }^{27}$ Kafka, Cartas a Felice.

${ }^{28}$ Véase supra llamado de nota 8.

${ }^{29}$ Hay muchas biografías que cuentan en los detalles estas historias, reportamos sólo un ejemplo por cada autor. Para Kierkegaard, véase Joakim Garff, Sak, trad. S. Davini y A. Scaramuccia, Roma: Castelvecchi, 2013, pp. 141-156; para Kafka véase Reiner Stach, Kafka, trad. C. Fortea, Barcelona: Acantilado, 2016, pp. 803-1736. 
interesante es que ambos decidieron, después de haber estado tan cerca, no acceder a la vida matrimonial.

Ahora bien, a continuación, nos proponemos analizar las motivaciones de ambos para tomar esta decisión atendiendo a las similitudes y las diferencias entre ellos. Esto nos llevará a reflexionar sobre las concepciones de la vida estética de ambos y sobre el papel que la escritura tuvo en sus existencias $^{30}$.

\section{Por qué Kierkegaard y Kafka decidieron no casarse}

Se ha hablado mucho de las motivaciones que llevaron a Kierkegaard a escoger una vida sin matrimonio. Antes de analizar por qué finalmente decidió no casarse, parece relevante dedicar unas palabras a su concepción del matrimonio. Para él, esta era una solución de vida fuertemente aconsejable, bien desde un punto de vista de perpetuación de la especie humana ${ }^{31}$, bien porque casarse fortalece el carácter ${ }^{32}$, bien porque es el digno final de una relación amorosa ${ }^{33}$, pero, sobre todo, porque el matrimonio tiene un origen divino $^{34}$. Empero, a pesar de todas estas motivaciones positivas, él decidió no casarse. ¿Por qué? La respuesta a este interrogante tiene que ver tanto con su filosofía como con su vida privada, que como ya hemos visto, en su caso, están fuertemente relacionadas.

Empezaremos analizando las razones personales que empujaron a Kierkegaard a cortar el noviazgo con Regine, y después pasaremos a las razones que el hombre de la vida estética aduce en contra del matrimonio.

Una de las consideraciones más importantes que subyace a toda la vida del escritor escandinavo es su profunda convicción de no poder escapar a la

${ }^{30}$ Como se ha dicho, nos parece que este resultado se puede lograr de manera bastante exhaustiva concentrándonos en el ejemplo práctico de sus decisiones en relación con la vida matrimonial, las cuales, como se verá en seguida, ciertamente marcaron profundamente la vida de ambos.

${ }^{31}$ Søren Kierkegaard, Diario intimo, Buenos Aires: Santiago Rueda-Editor, 1955, p. 438. 59-61.

32 Kierkegaard, Estética del matrimonio, Buenos Aires: Editorial Leviatán, 1991, pp.

${ }^{33}$ Ibíd., p. 35.

${ }^{34}$ Søren Kierkegaard, Etapas en el camino de la vida, Buenos Aires: Santiago RuedaEditor, 1951, en particular Palabras sobre el matrimonio, p. 186. Este tema lo encontramos tratado de manera muy profunda en Rodrigo Figueroa Weitzman, "Kierkegaard y el matrimonio”, Veritas, no. 30, marzo, especialmente la sección Razones para casarse, pp. 86-96. 
melancolía que lo atrapó durante su breve existencia. Él estaba convencido de que, a causa de un imprecisado pecado cometido por el padre años atrás, él debía convivir con una maldición que involucraba a toda su familia ${ }^{35}$. El filósofo nunca especificará cuál fue el pecado que signó la suerte de todos sus parientes, pero vivió toda su vida con la seguridad de que este acontecimiento había puesto una marca de infelicidad sobre toda su familia. La melancolía que acompañaba a Kierkegaard a lo largo de sus días, y que él atribuía a la culpa de su padre, tenía otra peculiaridad, era hereditaria. Entonces, si se hubiese casado, tanto su esposa como sus hijos habrían tenido que compartir su mismo destino:

Admitamos que me hubiera casado con ella. ¿Qué habría sucedido? En menos de un año se hubiera acongojado. Hay en mí (en ello consiste el lado bueno y el malo de mi naturaleza) algo de incorpóreo, algo que hace que nadie pueda enfrentarse conmigo cuando de compartir la vida cotidiana se trata, y entablar de este modo una relación real [...]. Yo era demasiado pesado para ella y ella demasiado pesada para $\mathrm{mi}^{36}$.

Adicionalmente, esta melancolía tenía otra particularidad que resulta fundamental para entender la elección de Kierkegaard en contra de la vida familiar: estaba relacionada con una misión que él tenía que cumplir, esto es, explicar el cristianismo a los cristianos ${ }^{37}$. Este objetivo, que está a la base de sus obras de escritor, tenía para él la máxima importancia y no quería ceder a aspectos que hubieran comprometido este tema. Desafortunadamente, el matrimonio habría sido incompatible con el compromiso que el escritor estimaba necesario para cumplir dicha tarea. En su vida no había espacio para dos cosas tan importantes y desgastantes, todo tenía que ser sacrificado en beneficio de su actividad de escritor, pues sólo dedicándose con toda su alma y su cuerpo a esta actividad se habría podido alcanzar el objetivo prefijado.

Esta imposibilidad de casarse para no robar tiempo a su tarea "divina", está relacionada con una de las motivaciones en contra del matrimonio que él explica por medio de uno de sus escritos estéticos: casarse comportaría

${ }^{35}$ En relación con la maldición, tenemos que recordar que Kierkegaard se crió en una familia particularmente desafortunada. Él y su hermano Peter Christian fueron los únicos de los siete hijos que sobrevivieron más de 33 años. De hecho, es famoso su misterioso aguijón en la carne que, según él, le habría impedido tener una vida feliz.

${ }^{36}$ Kierkegaard, Diario intimo, p. 300.

${ }^{37}$ Cfr. Regis Jolivet, El existencialismo de Kierkegaard, Madrid: Espasa-Calpe, 1952, p. 21. 
una pérdida de libertad. De hecho, podemos leer en qué términos expone este tema en La rotación de los cultivos:

Guárdese uno siempre de contraer una relación para toda la vida en cuyo seno se puede llegar a ser muchos. Por eso es siempre peligrosa la amistad y aún más el matrimonio. Es cierto que se dice que los desposados acaban siendo uno; pero éste es un dicho oscuro y místico. Al multiplicarse pierde uno la libertad y no puede calzarse las botas de viaje cuando le place, no puede vagar con veleidad. Si uno tiene esposa es difícil; si tiene esposa y quizá hijos, es arduo; si tiene esposa e hijos, es imposible ${ }^{38}$.

Hemos destacado el hecho de que el hombre estético considera el matrimonio como una pérdida de independencia, es decir, de libertad porque, como veremos después, este particular se revelará fundamental en la poética de Kafka, que pasamos a analizar enseguida, no sin antes resumir las razones que convencieron a Kierkegaard de no casarse, a pesar de su consideración positiva sobre el matrimonio: a) él estaba convencido de que casándose habría contagiado su melancolía a su esposa y a sus hijos; b) la vida matrimonial habría comportado abandonar su misión divina; y c) para el hombre estético, el matrimonio habría comportado una pérdida de libertad.

El caso de Kafka es igualmente interesante. Él estuvo, en dos oportunidades, muy cerca de casarse con su novia Felice Bauer, pero en ambas ocasiones el intento de matrimonio fracasó. Aquí hay muchas menos dudas en relación con las motivaciones que llevaron a Kafka a escoger la vida de soltero. Queremos empezar nuestro análisis reportando in extenso una carta que el escritor escribió al padre de Felice, en la cual explicaba sus motivaciones para anular la boda con su hija:

Con mis cartas he cegado a su hija, por regla general no era mi intención engañarla (aunque a veces sí quería engañarla porque sentía, y siento, amor por ella, y era terriblemente consciente de la incompatibilidad), y es tal vez precisamente, así como le he cerrado los ojos. No lo sé. Usted conoce a su hija, es una muchacha alegre, sana, segura de sí misma, que necesita estar rodeada de personas alegres, sanas, llenas de vida, para poder vivir. A mí me conoce usted solamente por la visita que les hice (casi me inclinaría a decir que esto debería bastar), además no puedo repetir lo que acerca de mí le he dicho a su hija en aproximadamente unas quinientas cartas. Por lo tanto, considere usted solamente este importantísimo punto: la totalidad de mi ser se orienta

${ }^{38}$ Kierkegaard, O lo uno o lo otro. Un fragmento de vida I, p. 303. 
hacia el hecho literario, hasta cumplir treinta años he venido manteniendo rigurosamente dicha orientación; si la abandonara dejaría de vivir. Todo cuanto soy y no soy se deriva de este hecho. Soy taciturno, insociable, hosco, egoísta, hipocondríaco y auténticamente enfermizo. En el fondo no lamento nada de esto, es el reflejo terrenal de una necesidad superior. (Naturalmente no son mis facultades personales lo que se pone aquí en cuestión, una cosa no tiene nada que ver con la otra.) En el seno de mi familia, rodeado de los seres más cariñosos, vivo sintiéndome más ajeno que un extraño. En el curso de los últimos años no habré hablado con mi madre, por término medio, más de veinte palabras diarias, con mi padre apenas si he intercambiado alguna vez otra cosa que no sean palabras de saludo. Con mis hermanas casadas y con mis cuñados no hablo en absoluto, sin por eso estar enfadado con ellos. Carezco del sentido de la convivencia familiar. ¿Podrá vivir su hija junto a un hombre semejante; ella, que, de acuerdo con su naturaleza de muchacha sana, está predestinada a una auténtica felicidad conyugal? ¿Habrá de soportar el llevar una vida monacal al lado de un hombre que, eso sí, la quiere como jamás será capaz de querer a nadie, pero que, obedeciendo a su ineluctable destino, se pasa la mayor parte del tiempo encerrado en su cuarto, o si no se va a dar solitarios paseos por las calles? ¿Habrá de soportar el vivir completamente separada de sus padres y familiares, y privada de casi cualquier otra relación, pues de lo contrario yo, que con gusto cerraría las puertas de mi casa hasta a mi mejor amigo, no podría ni pensar siquiera en la vida común conyugal? ¿Y esto es lo qué habría de soportar Felice? ¿Y para qué? ¿Acaso en aras de una literatura a sus ojos -y puede que incluso también a los míos- sumamente cuestionable? ¿En aras de tal cosa habría de vivir sola en una ciudad extraña, en el seno de una unión matrimonial que tal vez fuera más bien amor y amistad que auténtico matrimonio? No he dicho más que una ínfima parte de lo que quería decir. Ante todo: mi intención ha sido no disculpar nada. Entre su hija y yo no habría solución posible, la quiero demasiado. Ella se da excesivamente poca cuenta de las cosas, y pretende lo imposible, quizás sólo por compasión y por mucho que lo niegue. Ahora somos tres, iJuzgue usted! ${ }^{39}$

Leyendo el largo fragmento de esta carta podemos deducir cuáles pudieron haber sido las motivaciones de Kafka en contra del matrimonio, las que en realidad se pueden reducir a una sola. Por cuanto él hubiera tenido la intención de casarse y así empezar una vida socialmente aceptada por su familia y por la comunidad judía a la cual pertenecía, él se detuvo porque tenía la seguridad de que este estilo de vida le habría comportado abandonar

${ }^{39}$ Kafka, Cartas a Felice, pp. 465-466. Tenemos que precisar que este testimonio es uno de lo más ilustrativos de la postura kafkiana en relación con el matrimonio, y por esto consideramos suficiente poner nuestra atención sólo en esta epístola, en cuanto de aquí se pueden extraer todas las informaciones que necesitamos. 
su única vocación, la literatura. Como se ve en la carta que hemos citado, él no está dispuesto a abandonar la soledad necesaria para una prolífica actividad literaria, la cual estaría gravemente amenazada por la presencia de una esposa en su vida.

Adicionalmente, de esta carta podemos extraer otro dato útil para nuestro análisis: es evidente que también para Kafka el amor está a la base del matrimonio, en esta citación se ve muy bien cómo él se combate entre el amor por Felice y la pasión literaria. Es aquí donde entra en juego la lectura kafkiana del seductor kierkegaardiano: Kafka se ensimisma completamente en esta figura esbozada por Kierkegaard en sus obras estéticas ${ }^{40}$. Sólo así encuentra la fuerza para justificar su estilo de vida completamente antisocial que tiene como único fin escribir.

\section{Conclusiones}

Después de haber ilustrado las motivaciones por las cuales Kierkegaard y Kafka renunciaron a casarse, tenemos que cumplir con el objetivo que nos propusimos: ver cómo la estética de Kierkegaard influenció la poética de Kafka. Esto lo podemos determinar, por ejemplo, comparando las posturas de ambos en relación con el matrimonio.

Como hemos dicho, ambos pensaban que el amor estaba a la base del matrimonio, motivo por el cual les habría gustado casarse y comenzar una vida socialmente aceptable con las mujeres que amaban y que los amaban; sin embargo, para ambos la vida matrimonial habría significado renunciar a la actividad literaria (la escritura). Entonces, desde ya podemos destacar que el tema de la literatura es fundamental para entender la relación que existe entre ellos y el amor, pues es justamente en las diferentes concepciones de la vida literaria que tenemos que buscar lúmenes para el tema que estamos tratando.

De hecho, hay una enorme diferencia entre las dos interpretaciones del papel de la escritura por parte de ambos autores. Mientras que para Kierkegaard la actividad literaria era un medio para conseguir el fin de explicar el cristianismo a los cristianos, para Kafka la escritura era más bien el fin en sí mismo. Es más, una vez escribió que él era escritura ${ }^{41}$, pues había un ensimismamiento total entre su individualidad y la vida literaria.

${ }^{40}$ De nuestra misma opinión es Baioni, Kafka: letteratura ed ebraismo, p. 216,

${ }^{41}$ Ésta es una afirmación que se encuentra tanto en los Diarios en la fecha del 21 de 
De este modo, el rechazo del matrimonio a causa de la escritura tiene dos matices diferentes en los dos escritores. Para Kierkegaard, casarse habría significado renunciar a la misión de una vida orientada religiosamente, si bien probablemente habría comportado también una vida más feliz; por su parte, para Kafka casarse habría implicado renunciar a su misma naturaleza, sólo para seguir un estilo de vida socialmente aceptable, aunque totalmente incompatible con su razón de ser. Entonces, mientras que para Kierkegaard no casarse implicó una renuncia a una vida matrimonial, probablemente feliz; para Kafka, éste fue un acto de salvación respecto de una situación existencial que le habría representado un auténtico dolor, en relación con la imposibilidad de seguir adelante con su actividad literaria. En otras palabras: para Kierkegaard el estilo de vida estético era sólo la peor manera en la que el individuo podía conducir su vida; mientras que Kafka nunca logró ir más allá de dicho estilo de vida.

Ahora que hemos aclarado esto tenemos que precisar cómo Kafka se aprovechó de la estética de Kierkegaard para evitar la "trampa" matrimonial, valiéndose de la figura del seductor de Kierkegaard. Él se convenció de que una vida permeada en su totalidad por la literatura no tenía una salida distinta a conducir un estilo de vida casi idéntico al del seductor kierkegaardiano. En otras palabras, el escritor checo encontró en esta figura literaria la justificación a toda su situación existencial, aunque en los planes originarios del danés era una figura útil sólo para mostrar un estilo de vida autodestructivo. Ensimismándose en este patrón, Kafka logró encontrar una justificación a su manera de vivir, que era completamente incomprensible para su entorno familiar y cultural.

En fin, y retomando la ilación de todo el artículo, podemos afirmar que se encuentran trazas de esta influencia kierkegaardiana, no sólo en las cartas privadas de Kafka, sino también en sus obras literarias. Por todo esto pensamos que se puede declarar sin lugar a duda que, en la poética de Kafka, sobre todo en temas como seducción y amor, la estética de Kierkegaard tuvo una influencia considerable.

agosto de 1913, como en las Cartas a Felice a la fecha 14 de agosto de 1913. 


\section{Bibliografía}

Obras de Kierkegaard

Kierkegaard, Søren, Bucher des Richters. Ein Tagebücher 1833-1855, en Auszug aus dem Dänischen, ed. por H. Gottsched, Jena y Leipzig: Eugen Diederichs Verlag, 1905.

_ Diario intimo, Buenos Aires: Santiago Rueda-Editor, 1955.

_- Estética del matrimonio, Buenos Aires: Editorial Leviatán, 1991.

— La repetición. Temor y temblor, trad. de D. González y O. Parcero, Madrid: Trotta, 2019.

- O lo uno o lo otro. Un fragmento de vida I, trad. de Begonya Saez Tajafuerce y Darío González, Madrid: Trotta, 2006.

- O lo uno o lo otro. Un fragmento de vida II, trad. de Begonya Saez Tajafuerce, Madrid: Trotta: 2007.

_Etapas en el camino de la vida, Buenos Aires: Santiago Rueda-Editor, 1951.

\section{Otras obras consultadas}

Baioni, Giuliano, Kafka: letteratura ed ebraismo, Turín: Einaudi, 1984.

Davini, Simonella, La maschera estetica del seduttore, en Maschere kierkegaardiane, ed. por Leonardo Amoroso, Turín: Rosenberg\&Sellier, 1990.

Eilittä, Leena, "Art As religious Commitment: Kafka's Debt to Kierkegaardian Ideas and Their Impact on His Late Stories", German Life and Letters, vol. 53, no. 4, 2000, pp. 499-510.

Figueroa Weitzman, Rodrigo, "Kierkegaard y el matrimonio", Veritas, no. 30, 2014, pp. 83-104.

Garff, Joakim, Sak, trad. S. Davidi y A. Scaramuccia, Roma: Castelvecchi, 2013.

Hincapié Sánchez, Jennifer, De estética y seducción en "Los eróticos inmediatos, o el erotismo musical", en De ironía y seducción. Ensayos sobre Kierkegaard, ed. por Jennifer Hincapié Sánchez, Medellín: Editorial Universidad de Antioquia, 2019.

Jolivet, Regis, El existencialismo de Kierkegaard, Madrid: Espasa-Calpe, 1952.

La Rubia de Prado, Leopoldo, El laberinto kafkiano. Claves hermenéuticas para la comprensión de la obra de Franz Kafka y la categoría estética de lo "kafkiano", Tesis de Doctorado, Madrid: UNED, 1999.

Kafka, Franz, Cartas a Felice, trad. de P. Sarozábal, Madrid: Nórdica Libros, 2013. 
_Diarios (1910-1923), trad. de F. Formosa, Barcelona: Fabula Editorial Lumen, 2010.

_ El castillo, en Obras completas I, ed. por Jordi Llovet, trad. de Miguel Sáenz, Barcelona: Galaxia Gutenberg, 1999.

_ El proceso, en Obras completas I, ed. por Jordi Llovet, trad. de Miguel Sáenz, Barcelona: Galaxia Gutenberg, 1999.

Northey, Anthony, Family, en Franz Kafka in Context, ed. por Caroline Duttinger, Cambridge: Cambridge University Press, 2018.

Pellegrini, Giovanni, La legittimazione di sé. Kafka interprete di Kierkegaard, Turín: Trauben, 2001.

Rodríguez, Héctor, "La seducción estética y el amor infeliz en Søren Kierkegaard”, Cuadernos de filosofía latinoamericana, vol. 30, no. 101, 2009.

Stach, Reiner, Kafka, trad. C. Fortea, Barcelona: Acantilado, 2016.

Walsh Utterback, Sylvia, "Don Juan and the Representation of Spiritual Sensuousness", Journal of the American Academy of Religion, vol. 47, no. 4. 1979. 